\title{
Effects of preweaning injections of adrenalin on later open field behavior of rats'
}

NORMAN D. HENDERSON AND HOWARD C. EISNER

Wistar rats were given $0.0,0.4,1.2$, or $3.6 \mathrm{mg} / \mathrm{kg}$ injections of epinephrine at either 2 or 10 days of age. Three weeks later their open field behavior was compared to noninjected matched littermates. No age or dosage differences were found, but all injected groups defecated less than nontreated groups.

In reviewing some of the literature concerning early stimulation and later emotional behavior of rodents, Denenberg (1964) suggested that emotionality decreased as a monotonic function of the amount of stimulus input. This conclusion was based primarily on the fact that restricted or undisturbed rats generally show more fearful behavior than rats receiving prior handling or mild spaced shock. Although restriction, handling, and shock can be ranked on a "stimulus input" continurum, different combinations of basic processes are likely to be involved in each of these treatments. A more satisfactory examination of the relationship between stimulus input and later behavior would involve systematically increasing stimulation on a single dimension, such as intensity of shock. The use of shock and similar stimuli, however, increases the opportunity for Ss to develop conditioned fear associated with manipulation and/or cage removal, which in turn may alter later behaviors apart from the pure stimulation effects.

Based on a study involving drug administration to neonatal rats, Young (1964) suggested that psychopharmacological techniques could be used to study early development of certain classes of behaviors. The present study utilizes this approach by examining the changes in behavior of rats that result from varying dosages of epinephrine injected either early or late in the development of the pituitary-adrenal axis.

Method

Ss were 64 matched littermate pairs of Wistar rats. At weaning each $S$ was caged individually in a drawer type cage and undisturbed until adult testing. The testing apparatus consisted of two identical open fields 36 in. square with 24 in. black walls. The floor of each field was divided into four equal $18 \mathrm{in}$. quadrants by two photoelectric beams intersecting at right angles. When $S$ crossed either beam a count was registered. Suspended 18 in. above the center of the fleld was a $150 \mathrm{w}$ red reflector flood lamp providing an illumination of approximately $100 \mathrm{ft}$.-candles at the center of the field.

A 2 by 4 by 2 by 2 experimental design was used with Treatment (injected v. undisturbed), Dosage $(0.0,0.4$, 1.2 , or $3.6 \mathrm{mg} / \mathrm{kg}$ ), Age (2 or 10 days) and Sex being the main factors. On the day of treatment each experi- mental $\mathrm{S}$ was given three subcutaneous injections spaced $6 \mathrm{hr}$. apart. All 2-day Ss received .07 cc fluid whlle older Ss received $.15 \mathrm{cc}$ fluid. To avoid extra handling of experimental Ss, dosages were based on average weights of 2- and 10-day old rats in the colony. Matched control littermates were undisturbed until weaning and testing. Twenty-one days after injection Ss of an experimental-control pair were tested simultaneously in the two open fields for $5 \mathrm{~min}$. and defecation and number of beam crossings was recorded. This procedure was repeated on the following day.

Results

Since the number of boluses on each day roughly followed a Poisson distribution, the transformation $\sqrt{\mathrm{X}}+\sqrt{\mathrm{X}+1}$ suggested by Freeman \& Tukey (1950) was used on these data. Analysis of variance indicated that aside from older Ss defecating more than younger Ss $(F=4.3, \mathrm{df}=1 / 48, \mathrm{p}<.05)$, only the Treatment factor $(F=6.5, d f=1 / 48, p<.025)$ and the Treatment by Dosage by Sex interaction $(F=3.6, d f=3 / 48, p<.025)$ were significant. Table 1 summarizes the mean transformed defecation scores for males and females in each of the dosage groups. Injected groups at each dosage level defecated less than control groups. Within sexes two reversals occurred $(3.6 \mathrm{mg} / \mathrm{kg}$ males and $0.4 \mathrm{mg} / \mathrm{kg}$ females) which account for the significant higher order interaction.

Analysis of the transformed $(\sqrt{\mathrm{X}})$ activity scores indicated no significant differences, although injected groups at each dosage level were more active than their matched undisturbed groups.

Discussion

The results indicated that all that was necessary to alter Ss' later open field behavior was the injection itself. All injected groups showed a "handling effect"decreased defecation and increased open field activity. No differences in mortality were found between groups. Dosages, however, extended well above those shown to have behavioral and physiological effects with $5 \mathrm{mg} / \mathrm{kg}$ reported to be the LD50 for rats (Bames \& Eltherington,

Table 1. Transformed defecation scores for injected and noninjected groups at each dosage level

\begin{tabular}{|c|c|c|c|c|c|c|}
\hline \multirow{2}{*}{$\begin{array}{l}\text { Dose } \\
\mathrm{mg} / \mathrm{kg}\end{array}$} & \multicolumn{2}{|c|}{ Males } & \multicolumn{2}{|c|}{ Females } & \multicolumn{2}{|c|}{ Comb. Sexes } \\
\hline & $\ln \mathrm{j}$. & Cont. & $\ln i$. & Cont. & Inj. & Cont. \\
\hline 0.0 & 3.9 & 5.3 & 4. 1 & 5.1 & 4.0 & 5.2 \\
\hline 0.4 & 4.9 & 7.1 & 6.9 & 5.8 & 5.9 & 6.4 \\
\hline 1.2 & 3.2 & 5.4 & 4.3 & 5.0 & 4.2 & 5.2 \\
\hline 3.6 & 5.6 & 4.6 & 3.0 & 6.1 & 4.3 & 5.4 \\
\hline
\end{tabular}


1964). Apparently mimicing stress or "anxiety" effects through direct injection of adrenalin, either early or late in the development of the pituitary-adrenal axis, does not alter later "emotional" behavior.

The above results are surprising in the light of Young's (1964) finding that norepinephrine injected in 2- to 4-day old rats increased later defecation scores, while saline injection had no major effect. The current study employed matched E-C pairs within litters, however, while Young assigned complete litters to various experimental conditions. Using the whole-litter method makes it impossible to determine whether drug injections per se or interactions between mothers and offspring are responsible for apparent drug effects.

Young also allowed ss to remain outside their home cage for $15 \mathrm{~min}$. after injection, while in the current study Ss were returned immediately after treatment. Rats which have been subjected to relatively severe early massed stimulation such as shock, noise, or cold stress, have been shown to be more emotional than Ss receiving a more mild stimulation (Hutchings, 1963; Henderson, 1964). In these last two studies and to some extent in Young's experiment the noxious stimulation and Ss stress reaction occurred outside the home cage, while this was not the case in the current experiment. These findings suggest that fear conditioning, which has been found to play a role in stimulation effects by the time of weaning (Campbell \& Candland, 1961), may also occur in very young Ss.

\section{References}

Barnes, C. D., \& Eltherington, L. G. Drug dosage in laboratory animals. Berkeley: University of California Press, 1964.

Campbell, B. A., \& Candiand, D. K. Effects of prior shock on the emotionality of young rats in an open field. Canad. J. Psychol., $1961,15,1-5$.

Denenberg, v. H. Critical periods, stimulus input, and emotional reactivity: A theory of infantile stimulation. Psychol. Rev., 1964, 71, 335-351.

Freeman, M. F, \& Tukey, J. W. Transformations related to the square root. Ann. Math. Statist., 1950, 21, 607-611.

Henderson, N. D. Parameters which influence the effects of early treatment on later emotionality. Paper read at American Psychological Association, Los Angeles, September, 1964.

Hutchings, D. E. Early "experience" and its effect on later behavioral processes in rats: III Effects of infantile handling and body temperature reduction on later emotionality. Trans. Neu York Acad. Sci. Ser. II, Vol. 25, No. 8, June, 1963, 871-889.

\section{Note}

1. This research was supported by Grants GB-1863 and GE-6432 from the National Science Foundation. 